\title{
How Do Cytokines Trigger Genomic Instability?
}

\section{Ioannis L. Aivaliotis, ${ }^{1}$ Ioannis S. Pateras, ${ }^{1}$ Marilena Papaioannou, ${ }^{1}$ Christina Glytsou, ${ }^{1}$ Konstantinos Kontzoglou, ${ }^{2}$ Elizabeth O. Johnson, ${ }^{3}$ and Vassilis Zoumpourlis ${ }^{4}$}

\author{
${ }^{1}$ Molecular Carcinogenesis Group, Department of Histology and Embryology, School of Medicine, \\ National and Kapodistrian University of Athens, 11527 Athens, Greece \\ ${ }^{2}$ 2nd Department of Propedeutic Surgery, Laikon General Hospital, School of Medicine, \\ National and Kapodistrian University of Athens, 11527 Athens, Greece \\ ${ }^{3}$ Department of Anatomy, School of Medicine, National and Kapodistrian University of Athens, 11527 Athens, Greece \\ ${ }^{4}$ Institute of Biology, Medicinal Chemistry and Biotechnology, National Hellenic Research Foundation, 11635 Athens, Greece
}

Correspondence should be addressed to Ioannis L. Aivaliotis, ioaival@gmail.com and Vassilis Zoumpourlis, vzub@eie.gr

Received 25 January 2012; Accepted 8 April 2012

Academic Editor: Vassilis Gorgoulis

Copyright (C) 2012 Ioannis L. Aivaliotis et al. This is an open access article distributed under the Creative Commons Attribution License, which permits unrestricted use, distribution, and reproduction in any medium, provided the original work is properly cited.

Inflammation is a double-edged sword presenting a dual effect on cancer development, from one hand promoting tumor initiation and progression and from the other hand protecting against cancer through immunosurveillance mechanisms. Cytokines are crucial components of inflammation, participating in the interaction between the cells of tumor microenvironment. A comprehensive study of the role of cytokines in the context of the inflammation-tumorigenesis interplay helps us to shed light in the pathogenesis of cancer. In this paper we focus on the role of cytokines in the development of genomic instability, an evolving hallmark of cancer.

\section{Introduction}

Contemporary approaches in cancer research have been influenced by the accumulating data unveiling the importance of inflammatory components in the tumor microenvironment. It is becoming more clearly evident that inflammation demonstrates a dualism effect on cancer development in close resemblance to a ying-yang pattern. Inflammation may exhibit either a pro- or an antitumorigenic effect. Cytokines possess a central role in the inflammatory component implicated in the interplay between the host's stromal cells and the tumor cells during tumorigenesis. In this paper we are shedding light on the molecular pathways linking cytokines with the induction of genomic instability, an evolving hallmark of cancer.

\section{Interrelation of Inflammation and Carcinogenesis}

Rudolf Virchow was the first to observe, back in the nineteenth, the presence of leukocytes inside tumors and this observation was the first indication of a possible linkage between inflammation and cancer. The last decade intensive research has focused on the molecular pathways involved in the above linkage and it is now well understood that chronic inflammation plays a significant role in the carcinogenesis process [1].

In 1909, Paul Ehlrich proposed the immunosurveillance theory, later established by Thomas and Burnet, which supports the tumor suppressive role of the immune system [24]. Dunn and his colleagues suggested in 2004 that a new theory should be adopted to describe the relationship between the immune response and tumorigenesis, called immunoediting [5]. According to this theory, three distinct stages exist describing the interrelation between immunity and carcinogenesis. The first stage, termed elimination, represents the period in which the immune system, through successful immunosurveillance, destroys precancerous and cancerous cells. In equilibrium, the second stage, cancer cells have begun to develop abilities to avoid immunosurveillance mechanisms but the balance between "immune patrol" and tumorigenesis is still preserved. In the third stage, named 
escape, the cancer cells manage to evade the surveillance system of the organism, resulting in aberrant cell proliferation and tumor development. Interestingly, it seems that the immune response to the tumor causes an "immunosculpting" effect on cancer cells that enables them to resist immunological recognition or to exert enhanced defense mechanisms against immunosurveillance [5].

Recent advances in cancer biology research have demonstrated that a chronic indolent inflammation environment harbors potential tumor promoting mechanisms [1]. According to Hanahan and Weinberg, one of the emerging hallmarks of cancer is the ability to escape immunosurveillance and an enabling characteristic for the acquisition of these capabilities is the inflammation propagated by the tumor [6]. Compelling evidence of the last decade supports the notion that the inflammatory microenvironment is important for the survival of tumors [1]. It seems that inflammatory cells of the innate immunity usually display a tumor promoting role whereas cells of adaptive immunity appear to have a tumor suppressive effect $[1,7]$.

Inadequate pathogen eradication or continuous exposures to chemical carcinogens preserve a chronic inflammation environment that may enhance tumorigenesis [8]. There is evidence supporting that several unresolved inflammatory reactions following persistent pathogen infection promote human malignancies [9]. Pathogens contain specific patterns, known as pathogen-associated molecular patterns (PAMPs), which are recognized by host receptors, named pattern recognition receptors (PRRs), including Tolllike receptors (TLRs), nucleotide-binding oligomerization domain-like receptors (NOD-like) receptors, C-type lectin receptors (CLRs), and triggering receptors expressed on myeloid cells (TREMs) [10, 11]. The binding between PAMPs and PRRs leads to inflammation-related cell activation and triggers host immune defense mechanisms against foreign pathogens [10]. In relation to the previous part, it is well established that chronic viral hepatitis B and C is strongly associated with the development of hepatocellular carcinoma. In this case, excessive host reaction towards the viral infection is believed to play a significant role for the inflammation-mediated liver carcinoma. On the other hand and not mutually exclusive there are several viral infections in which the virus itself through its oncogenic potential is mainly responsible for the cancer development [12]. Human Papilloma Virus (HPV) infection is associated with cervical cancers and Epstein-Barr infection bears significant association with Burkitt lymphoma and nasopharyngeal carcinoma. Particular types of HPV produce the E6 and E7 oncoproteins which interfere with the p53 and Retinoblastoma protein $(\mathrm{pRb})$ pathways, respectively. Epstein-Barr virus (EBV) latent membrane protein 1 (LMP1) is critical for EBV-induced cellular transformation through the activation of NF- $\kappa \mathrm{B}$ (analyzed hereinafter), a transcription factor promoting cell survival [13].

In the context of chemically induced carcinogenesis, a typical example involves cigarette smoking, in which the tumorigenic activity is partially attributed to its ability to induce chronic inflammation [14]. Also asbestos or silica exposure may cause inflammation of the lung and subsequent bronchial carcinoma [15]. The mechanism of the induced inflammation by the above inhaled particles occurs by means of prointerleukin- $1 \beta$ (IL- $1 \beta$ ) processing by the inflammasome $[1,16]$. The inflammasome is a protein complex which includes two caspase-1 molecules, is related to cryopyrin protein, and leads to IL- $1 \beta$ cross-activation and maturation [17].

\section{Cellular Context and Cytokine Signaling in the Tumor Microenvironment}

The cellular context of the tumor's microenvironment includes cancer cells and surrounding stromal cells (involving fibroblasts, endothelial cells, pericytes, and mesenchymal cells) along with the infiltrating cells of the innate and adaptive immunity [1]. Innate immune cells include macrophages, myeloid-derived suppressor cells (MDSCs), neutrophils, and mast, dendritic, and natural killer (NK) cells, while adaptive immune cells consist of $\mathrm{T}$ and $\mathrm{B}$ lymphocytes. The only immune cells with no known tumor promoting role to date are NK cells [1]. MDSCs share common characteristics with macrophages, neutrophils, and dendritic cells and they help in tumor angiogenesis as well as suppression of antioncogenic immune responses [18, 19]. Tumor-associated macrophages (TAMs) and $\mathrm{T}$ cells are among the most frequently observed cells within the tumor microenvironment. TAMs are a heterogeneous cell population which evidently exerts a very significant role in tumor cell survival, growth, and progression and can be considered obligate partners for tumor cell migration, invasion, and metastasis $[20,21]$.

The interaction between the epithelial and stromal cells comprising the inflammatory microenvironment is mediated by a class of molecules named as cytokines. Cytokines are cell-signaling protein molecules with effects on intercellular communication; they include interleukins, lymphokines, and chemokines. Interleukins were initially observed to be expressed by leukocytes and present immunoregulatory action. Lymphokines are produced by lymphocytes and include IL-2, IL-3, IL-4, IL-5, IL-6, GMC-SF (Granulocyte-macrophage colony-stimulating factor), and IFN- $\gamma$ (Interferon-gamma). Chemokines are chemoattractant cytokines and are named this way due to their ability to control leukocyte migration to inflammation sites through chemotaxis $[22,23]$. The nomenclature of chemokines is based on the number and location of the $\mathrm{N}$-terminal cysteine residues, divided in four different groups: CXC, CC, CX3C, and C [23].

In accordance with increased expression of pro- or antiinflammatory cytokines and to tumor progression, TAMs may be classified into $M_{1}$ and $M_{2}$ types. $M_{1}$ macrophages are mostly found in early stage tumor development and may release proinflammatory cytokines (TNF-a, IL-1, IL-6, IL-12, IL-23) and chemokines CXCL19 and CXCL10. Their physiological role involves Th1/Th17 cellular responses and NK cell development and differentiation. $\mathrm{M}_{2}$ macrophages may be mostly found in more established tumors, show increased expression of IL-10 and transforming growth 
factor $\beta$ (TGF- $\beta$ ) as well as chemokines CCL17, CCL22, and CCL24, and are considered to promote tumor angiogenesis. This subtype of TAMs encourages Th2 and regulatory T cells (Tregs) recruitment $[1,7]$. According to their effector functions, $T$ cells can be subdivided in CD8+ cytotoxic $T$ cells (CTLs) and CD4+ helper T (Th) cells, including Th1, Th2, and $\mathrm{T}$ regulatory (Treg) cells [1]. $\mathrm{T}$ cells may exhibit either antitumor immune responses or promote tumor growth $[1,24]$.

The mechanisms of inflammation-mediated tumor promotion involve secretion of specific cytokines by both inflammatory and tumor cells as well as activation of transcription factors, mainly (Nuclear Factor- $\kappa \mathrm{B}$ ) NF- $\kappa \mathrm{B}$, (Signal Transducers and Activators of Transcription) STAT3, and (Activator Protein-1) AP 1. NF- $\kappa$ B and STAT3 expression can be detected in most cancers and these transcription factors activate genes responsible for cell survival, proliferation, angiogenesis, invasiveness, and production of cytokines [1, $25,26]$. NF- $\kappa$ B belongs to a family of transcription factors that regulate the secretion of many inflammatory cytokines, specific adhesion molecules, and the prostaglandin biosynthetic pathway. It also regulates the expression of antiapoptotic proteins and angiogenic factors in a tissue-specific manner $[15,27]$. There are three distinct activation pathways of NF- $\kappa \mathrm{B}$, the classical, the alternative, and the atypical pathways, and all seem to support tumorigenesis $[18,28,29]$. The classical pathway is triggered by pathogen infection, T-cell receptor (TCR) engagement, and proinflammatory cytokines, such as IL- 1 and TNF- $\alpha[28,29]$. The NF- $\kappa$ B alternative pathway is triggered by cytokines belonging to the TNF family and involves the IKK $\alpha$ homodimer and the p52/RelB transcription factors $[18,28]$. Finally, the atypical $\mathrm{NF}-\kappa \mathrm{B}$ pathway is IKK independent and is triggered by several stimuli such as hypoxia and hydrogen peroxide attack of the cells [29]. STAT3 activation induces the expression of $B c l 2$ and $B c l-x L$ antiapoptotic genes, Cyclin D1 or $c$ $M y c$ proliferation genes, and VEGF (vascular endothelial growth factor) angiogenesis promoting gene $[18,27]$. AP1 is a dimeric transcription factor composed of members of the Jun, Fos, activating transcription factor (ATF) and musculoaponeurotic fibrosarcoma (Maf) protein families. Several growth factors and cytokines induce MAPK signalling pathway which in turn activates AP-1 [30].

Cytokine IFN $-\gamma$ most frequently produced by cytotoxic CD8+ and CD4+ Th1 $\mathrm{T}$ cells has been recognized as a dominant tumor-inhibitory force (Table 1). On the other side, the cytokines interleukin-6 (IL-6), TNF- $\alpha$, IL-1 $\beta$, and IL-23 are mostly considered as tumor promoting [7]. Secretion of the latter cytokines is mainly induced by tumor associated macrophages and myeloid-derived suppressive cells [7]. One of the previously mentioned cytokines, macrophage-derived IL-1, was indicated to promote both inflammation and angiogenesis under a hypoxic environment which in turn ascertains the important role of IL-1 in inflammation-mediated tumorigenesis [31]. Additionally, IL- $1 \beta$ has recently been shown to induce a subset of MDSC in the tumor microenvironment capable of suppressing the development and function of NK cells [32]. Proinflammatory cytokines include IL-2, IL-6, IL-11, IL-15, IL-17,
IL-23, TNF- $\alpha$, and chemokine IL-8 and anti-inflammatory cytokines include IL-4, IL-10, IL-13, transforming growth factor $\beta$ (TGF- $\beta$ ) and interferon (IFN) $\alpha[22,33]$. Proinflammatory cytokines, such as IL-1 and TNF- $\alpha$ which in turn stimulate IL-8, may also stimulate chemokines $[22,34]$.

An interesting example of cytokine-mediated carcinogenesis is human malignant mesothelioma which may be provoked by chronic exposure to asbestos. TNF- $\alpha$ displays a tumor promoting role in this type of cancer by helping the survival of the mesothelial cells which, in turn, have been damaged by asbestos exposure and may develop mutagenic phenotypes rendering them susceptible to carcinogenesis $[10,35]$. TNF- $\alpha$ favors the survival of tumor cells by inducing the expression of antiapoptotic genes encoded in an NF- $\kappa$ Bdependent manner [10]. As a result, TNF- $\alpha$ - which may be released by host as well as cancer cells-significantly influences the initiation and progression stages of all cancer types [10]. Similarly, IL-6 exerts a tumor promoting role by enhancing cell cycle progression and suppressing apoptosis. Its signaling transduction pathway is induced by STAT3 transcription factor $[10,21]$. IL-17 triggers the secretion of TNF- $\alpha$, IL- 6 , and IL- $1 \beta$ proinflammatory cytokines and is produced by IL-23-dependent STAT3 activation $[10,36]$. IL23 has similar functions to IL-17, induces IFN- $\gamma$, and IL12 production by activated $\mathrm{T}$ cells, and leads to enhanced proliferation of memory $\mathrm{T}$ cells $[10,37]$. IL-10 activates STAT3 transcription factor but has an opposite effect in carcinogenesis to IL-6 [10]. Additionally it inhibits NF- $\kappa$ B activation and in this manner also inhibits production of TNF- $\alpha$, IL-6, and IL-12 [10, 38]. IL-10 probably exhibits its tumor suppressive role by inhibiting the production of the above mentioned proinflammatory cytokines [10]. IL10 may also exert protumorigenic activity through STAT3 activation by upregulating $B c l 2$ and $B c l-x L$ antiapoptotic genes, therefore confirming its dual role in the process of carcinogenesis $[10,39]$. Other cytokines have a known dual function in carcinogenesis (Table 1). Interestingly, TGF- $\beta$ may exert a tumor suppressive role in the beginning of the process and a tumor promoting role at the late stages of carcinogenesis [40].

Lessons for the mechanisms implicated in inflammationassociated carcinomas have paradoxically been taken by the study of cellular senescence [41]. It has been shown that senescent cells are metabolically active and secrete several factors that may alter their own as well as the tumor microenvironment [42]. The phenomenon of such secretion by the senescent cells has been termed senescence-associated secretory phenotype (SASP) [43]. SASP acts in a cellautonomous paracrine manner and has both a bright side, favoring senescence in normal or low-grade preneoplastic cells, as well as a dark side, facilitating evasion of senescence in high grade preneoplastic or cancerous cells [44]. The SASP involves a number of inflammatory cytokines, such as IL6 and chemokine IL-8, which constitute two of its prominent components [43]. It has been demonstrated that the proinflammatory cytokines IL- 6 and IL- 8 are upregulated by persistent DNA Damage Response (DDR) activation which in turn boost the DDR signaling pathway forming a positive feedback loop [43]. Of note, IL-6 and IL-8 are known to play 
TABLe 1: Potential pro- and antitumorigenic roles of cytokines.

\begin{tabular}{|c|c|c|c|c|}
\hline Cytokine & Protumorigenic role & Antitumorigenic role & $\begin{array}{l}\text { Unspecified yet role } \\
\text { in tumorigenesis }\end{array}$ & References \\
\hline IL- $1(\alpha$ and $\beta)$ & $\begin{array}{l}\text { Tumor growth, invasion and } \\
\text { metastasis, mainly through the } \\
\text { action of IL-1 } \beta \text { in promoting } \\
\text { local inflammatory responses } \\
\text { as well as angiogenesis. }\end{array}$ & $\begin{array}{l}\text { Restraint of tumor growth } \\
\text { through activation of innate } \\
\text { and specific immune effector } \\
\text { mechanisms mainly through } \\
\text { the action of IL-1 } \alpha \text {. }\end{array}$ & & {$[17]$} \\
\hline IL-2 & & $\begin{array}{l}\text { (i) Stimulates growth, } \\
\text { differentiation, and survival of } \\
\text { cytotoxic T cells } \\
\text { (ii) Induces differentiation } \\
\text { and proliferation of NK cells }\end{array}$ & & {$[53]$} \\
\hline IL-3 & & & $\begin{array}{l}\text { Stimulates the } \\
\text { differentiation and } \\
\text { growth of } \\
\text { multipotent } \\
\text { hematopoietic stem } \\
\text { cells }\end{array}$ & {$[54]$} \\
\hline IL-4 & $\begin{array}{l}\text { (i) Decreases the production } \\
\text { of Th1 cells, macrophages, } \\
\text { and IFN-gamma } \\
\text { (ii) Has been shown to drive } \\
\text { dedifferentiation, mitogenesis } \\
\text { and metastasis in } \\
\text { rhabdomyosarcoma }\end{array}$ & $\begin{array}{l}\text { Stimulation of activated B-cell } \\
\text { and T-cell proliferation, and } \\
\text { differentiation of CD4+ } \\
\text { T-cells into Th2 cells }\end{array}$ & $\begin{array}{l}\text { IgE and class II } \\
\text { MHC expression on } \\
\text { B cells }\end{array}$ & {$[55]$} \\
\hline IL-5 & & & $\begin{array}{l}\text { (i) Stimulates B cell } \\
\text { growth } \\
\text { (ii) Stimulates } \\
\text { eosinophil growth } \\
\text { and function }\end{array}$ & {$[56]$} \\
\hline
\end{tabular}

(i) Promotion of tumor cell proliferation and inhibition of their apoptosis through activation of STAT-3.

IL-6 (ii) Facilitation of senescence evasion in high-grade preneoplastic or cancerous cells through mechanisms of SASP.

(iii) Favours metastasis (i) Mediator of the acute phase response

(ii) Induction of senescence in normal or low grade preneoplastic cells.
Stimulates the differentiation of multipotent hematopoietic stem

cells

Stimulates proliferation of $\mathrm{B}$ cells, T cells, and NK cells
Significant role in tumor growth, angiogenesis,

IL-8 epithelial to mesenchymal transition (EMT) and invasiveness (i) Induction of chemotaxis in its target cells (neutrophils, granulocytes)

(ii) Induction of senescence in normal or low-grade preneoplastic cells.

(i) Potential role in tumorigenesis due to antiapoptotic and growth

IL-9 factor activities

(ii) Deregulated IL-9 response

may lead to malignant

transformation through Jak/STAT activation

Regulation of

hematopoietic cells 
Table 1: Continued.

\begin{tabular}{|c|c|c|c|c|}
\hline Cytokine & Protumorigenic role & Antitumorigenic role & $\begin{array}{l}\text { Unspecified yet role in } \\
\text { tumorigenesis }\end{array}$ & References \\
\hline IL-10 & $\begin{array}{l}\text { Potential tumor promoting } \\
\text { activity through activation of } \\
\text { STAT3 and consequent } \\
\text { upregulation of BCL-2 or } \\
\text { BCL-XL antiapoptotic genes. }\end{array}$ & $\begin{array}{l}\text { (i) Enhances B-cell survival, } \\
\text { proliferation, and antibody } \\
\text { production. } \\
\text { (ii) Inhibition of tumor } \\
\text { development and progression } \\
\text { through inhibition of NF- } \kappa \text { B } \\
\text { activation, TNF- } \alpha \text {, IL- } 6 \text {, and } \\
\text { IL- } 12 \text {. } \\
\text { (iii) Suppression of angiogenesis } \\
\text { through inhibition of the tumor } \\
\text { stroma. }\end{array}$ & & {$[10,59]$} \\
\hline
\end{tabular}

(i) Regulator of

haematopoiesis

IL-11

(ii) Stimulation of

megakaryocyte

maturation

\begin{tabular}{|c|c|c|c|c|}
\hline & & & & \\
\hline IL-12 & & $\begin{array}{l}\text { (i) Stimulates the growth and } \\
\text { function of T cells } \\
\text { (ii) Stimulates the production of } \\
\text { IFN- } \gamma \text {, TNF- } \alpha \\
\text { (iii) Induces cell-mediated } \\
\text { immune responses } \\
\text { (iv) Exhibits antiangiogenic } \\
\text { activity }\end{array}$ & & {$[61]$} \\
\hline IL-13 & & & Induces IgE secretion & {$[62]$} \\
\hline IL-14 & & & $\begin{array}{l}\text { Regulates the growth } \\
\text { and proliferation of B } \\
\text { cells }\end{array}$ & {$[63]$} \\
\hline IL-15 & & $\begin{array}{l}\text { (i) Stimulates growth, } \\
\text { differentiation and survival of } \\
\text { cytotoxic T cells } \\
\text { (ii) Induces differentiation and } \\
\text { proliferation of NK cells }\end{array}$ & & {$[53]$} \\
\hline IL-16 & & $\begin{array}{l}\text { Chemoattractant for certain } \\
\text { immune cells expressing the cell } \\
\text { surface molecule CD } 4 \text {. }\end{array}$ & & {$[64]$} \\
\hline IFN- $\gamma$ & & $\begin{array}{l}\text { (i) Produced by cytotoxic CD } 8+ \\
\text { and CD } 4+\text { Th1 T cells } \\
\text { (ii) Exhibits an overall significant } \\
\text { tumor inhibitory action. }\end{array}$ & & {$[1,7]$} \\
\hline TGF- $\beta$ & $\begin{array}{l}\text { Tumor promoting role at the } \\
\text { late stages of carcinogenesis }\end{array}$ & $\begin{array}{l}\text { Tumor suppressive role in the } \\
\text { beginning of carcinogenesis }\end{array}$ & & {$[40]$} \\
\hline OPN & $\begin{array}{l}\text { Implicated in enhanced } \\
\text { metastasis and invasion of } \\
\text { tumor cells }\end{array}$ & & & {$[68]$} \\
\hline CCL2 & $\begin{array}{l}\text { (i) Induces the recruitment of } \\
\text { macrophages } \\
\text { (ii) Induces angiogenesis and } \\
\text { matrix remodeling } \\
\text { (iii) Promotes prostate cancer } \\
\text { cell proliferation, migration, } \\
\text { invasion, and survival }\end{array}$ & & & [69] \\
\hline CCL21 & & $\begin{array}{l}\text { (i) Immune-mediated antitumor } \\
\text { response (chemoattraction of B } \\
\text { cells and NK cells to the lymph } \\
\text { nodes) } \\
\text { (ii) Angiostatic effect }\end{array}$ & & {$[70,71]$} \\
\hline
\end{tabular}


Table 1: Continued.

\begin{tabular}{|c|c|c|c|c|}
\hline Cytokine & Protumorigenic role & Antitumorigenic role & $\begin{array}{l}\text { Unspecified yet role } \\
\text { in tumorigenesis }\end{array}$ & References \\
\hline CCL16 & & $\begin{array}{l}\text { Augments the cytotoxic } \\
\text { activities of effector T cells }\end{array}$ & & {$[72]$} \\
\hline CXCL12 & $\begin{array}{l}\text { (i) Suppress antitumor } \\
\text { immunity in the tumor } \\
\text { microenvironment } \\
\text { (ii) Regulates trafficking of } \\
\text { immature and maturing } \\
\text { immune cells } \\
\text { (iii) Promotes angiogenesis } \\
\text { (iv) Facilitates metastasis }\end{array}$ & & & {$[73]$} \\
\hline
\end{tabular}

NK cells: Natural Killer cells; IgE: Immunoglobulin E; MHC: Major Histocompatibility Complex; OPN: Osteopontin.

a significant role in tumor growth, angiogenesis, epithelial to mesenchymal transition (EMT), and invasiveness [43, 45]. The aforementioned part indicates that the IL-6/IL-8 duet seems to exert both anti- as well as protumorigenic functions. IL- 1 proinflammatory cytokine (both $\alpha$ and $\beta$ forms) is also a SASP component secreted at lower levels compared to IL-6/IL- 8 and interestingly IL- $1 \alpha$ regulates the signaling network that leads to the expression of the latter duet [46].

\section{Cytokine-Mediated Growth Signaling, Replication Stress, and Genomic Instability}

Recently it has been proposed that genomic instability is an evolving hallmark of cancer and Hanahan and Weinberg (2011) established that it constitutes an enabling characteristic for the acquisition of the essential functions (hallmarks) of a cancerous cell $[6,47]$. Genomic instability is present in most human cancer types and has various forms. The most frequently occurring one is chromosomal instability (CIN) which involves structural and numerical chromosomal changes that occur in cancer cells over time [47]. Another common form is microsatellite instability (MIN or MSI) which is caused by alterations in DNA mismatch repair genes and leads to changes in the number of oligonucleotide repeats in microsatellite sequences [47]. Genomic instability is observed from early stages of cancer development, even before the acquisition of the cell's cancerous phenotype [48]. CIN is more frequently observed in human cancers compared to MIN and this might be explained by the formation of double-strand breaks (DSBs) in precancerous lesions and cancers according to the oncogene-induced DNA damage model [49].

Recent studies have unveiled the potential effects of enhanced growth signalling in age and/or age-related diseases, such as cancer. The proposed mechanism involves the induction of DNA replication stress which leads to the formation of DNA double-strand breaks (DSBs), favouring genomic instability and tumorigenesis $[50,51]$. Indeed, upregulation of growth-signalling pathways in all eukaryotes has been shown to impact cellular processes leading to increased oxidative DNA damage and replication stress in a correlative manner. DNA replication stress may occur by any mechanism causing slow progression or stalling of DNA replication forks and, as a result, compromise proper DNA replication [50]. The structural characteristics of the replicating DNA strands are greatly responsible for the induction of replication stress-induced DNA damage, as any lesions of the single-strand templates within the unfolded DNA at the sites of the replication forks subsequently cause DSBs. Consequently, the genetic sequence harbouring DSBs is rendered highly susceptible to serious gene rearrangements and genomic instability. Contemporary studies have clearly shown the activation of the replication stress-induced DNA damage response (DDR) pathway at the earliest stages of cancer development underlying its significance in carcinogenesis $[48,52]$.

Several cytokines exhibit growth factor activity. The most significant cytokines to date designated as growth factors are the following: Epidermal Growth Factor (EGF), PlateletDerived Growth Factor (PDGF), Fibroblast Growth Factor (FGF), TGF- $\alpha$, TGF- $\beta$, Erythropoietin, Insulin-Like Growth Factor 1 (IGF-1), Insulin-Like Growth Factor 2 (IGF-2), IL-1, IL-2, IL-6, IL-8, TNF- $\alpha$, TNF- $\beta$, INF- $\gamma$, and Colony Stimulating Factors (CSFs) (Table 1). Within this context a potential mechanism linking persistent chronic inflammation with carcinogenesis is through the activity of growth-promoting cytokines in the inflamed tissue. It has been previously shown that the injection of adenoviral vectors expressing a cocktail of growth factors (including fibroblast growth factor, stem cell factor, and endothelin-3) in human skin xenografts causes allelic imbalance in common fragile sites (CFSs), suggesting the formation of DSBs through replication stress [48]. In accordance with this, the presence of several growthpromoting cytokines within the inflammatory milieu for a prolonged period of time may induce replication stress and subsequent DSBs (Figure 1). In a rat silica model of inflammation-induced lung cancer the presence of the DNA damage response marker $\gamma \mathrm{H} 2 \mathrm{AX}$ was observed from early hyperplastic tissues, in bronchiolar hyperplasia, which supports the previous statement [74]. In another study the addition of IGF-1 or IGF-2 in human peripheral blood lymphocytes already incubated with bleomycin further increased the expression of p53 and the rate of chromosome aberrations, suggesting potential implication of DDR activation [75]. Overall, these findings indicate a potential role 


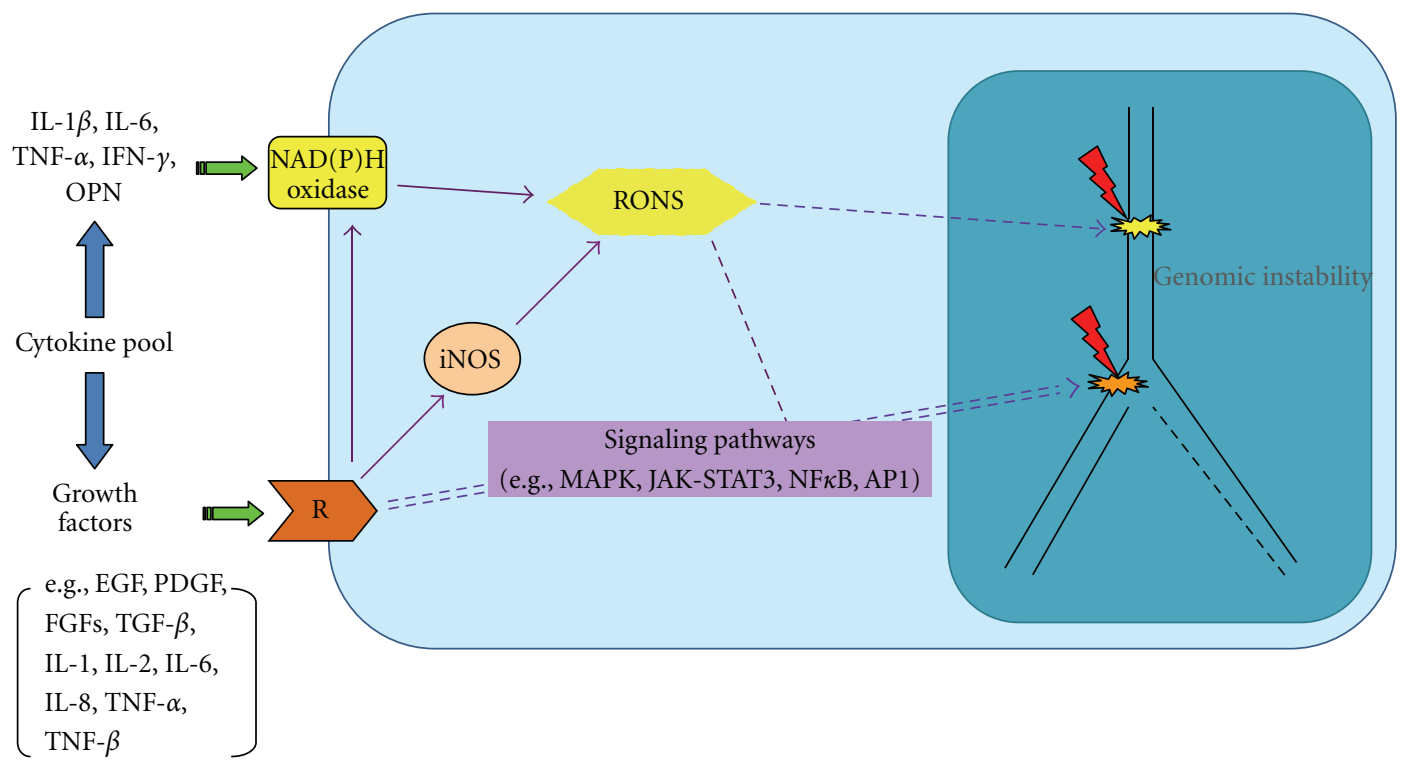

FIGURE 1: Schematic presentation of the proposed mechanism by which cytokines may promote genomic instability in chronic inflammatory conditions. Cytokines with growth factor activity may promote replication stress favouring the formation of DSBs. In addition, several cytokines induce the formation of RONS which in turn may cause DNA damage, including DNA cross-links, single- or double-strand breaks, and oxidative DNA damage with formation of 8-hydroxydeoxyguanosine (8-OHdG). Both mechanisms may provide a mechanism linking cytokine expression with genomic instability. MAPK: mitogen-activated protein kinase; JAK-STAT3: Janus kinase - Signal Transducer and Activator of Transcription 3; NF- $\kappa$ B: Nuclear Factor $-\kappa B$; AP-1: Activator Protein 1; OPN: Osteopontin; R: Receptor; RONS: Reactive Oxygen/Nitrogen Species; NAD $(\mathrm{P}) \mathrm{H}$ oxidase: Nicotinamide Adenine Dinucleotide Phosphate-oxidase; iNOS: inducible Nitric Oxide Synthase.

of cytokines with growth factor activity in the promotion of genomic instability through replication stress-induced DNA damage.

\section{Cytokines and Oxidative/Nitrosative Stress}

Reactive Oxygen and Nitrogen Species (RONS) are the free radical forms of oxygen and nitrogen, respectively. Free radicals contain one or more unpaired electrons rendering them highly reactive molecular metabolites [76, 77]. RONS are produced by endogenous as well as exogenous sources. Endogenous sources include metabolic reactions, such as electron transport reactions in the mitochondrial respiratory chain, metal reactions, and cells of the innate immune system, such as neutrophils and macrophages, during inflammatory responses $[33,77]$. Exogenous sources include atmosphere pollutants, ionizing and nonionizing radiation, several carcinogenic compounds, and metal ions [77].

The most commonly generated Reactive Oxygen Species (ROS) in cells are the superoxide anion $\left(\mathrm{O}_{2}^{-\bullet}\right)$, hydrogen peroxide $\left(\mathrm{H}_{2} \mathrm{O}_{2}\right)$, and the hydroxyl radical $\left(\mathrm{OH}^{\bullet}\right)$. The NADPH oxidase is an enzyme that plays the role of an electron donor and generates $\mathrm{O}_{2}^{-}$from oxygen in the body [78]. This enzyme can also lead to the production of $\mathrm{H}_{2} \mathrm{O}_{2}$ on neutrophil membranes [77]. NADPH oxidase exists in both phagocytes and nonphagocytes and has five known isoforms (NOX 1-5) as well as two reported related enzymes (DUOX 1-2) to date [78]. Nitric oxide $\left(\mathrm{NO}^{\bullet}\right)$ is a reactive free radical that generates additional Reactive Nitrogen Species
(RNS) and is more stable in a hypoxic environment than in normal oxygen tension conditions $[33,77]$. $\mathrm{NO}^{\bullet}$ is generated by the enzyme nitric oxide synthase (NOS) during the metabolization of L-arginine to citrulline [77, 79]. This enzyme exists in three isoforms in mammalian cells which consist of the neuronal (n)NOS, the endothelial (e)NOS, and the inducible (i)NOS [22, 80]. The nNOS and eNOS isoforms are constitutively expressed and produce low levels of $\mathrm{NO}^{\circ}$, while iNOS produces high levels of nitric oxide only upon inflammatory stimuli $[22,33]$. The nNOS and eNOS isoforms generate $\mathrm{NO}^{\bullet}$ with a neurotransmitting and vasodilating role, respectively, while the iNOS isoform produces $\mathrm{NO}^{\bullet}$ as a mediator of the inflammatory response $[33,81]$.

RONS play a dual role in the cell, at low concentrations they are beneficial exhibiting several physiological functions in cellular responses (such as cellular signaling pathways and mitogenic responses), whereas at high concentrations they are detrimental for its integrity [77, 82, 83]. Excessive ROS and RNS production leads to oxidative and nitrosative stress, respectively. In order to counteract the harmful effects of free radicals the cell has evolved several defense mechanisms. These mechanisms involve the action of enzymatic, such as superoxide dismutase (SOD), catalase, glutathione peroxidase (GPx), and nonenzymatic antioxidants, such as Vitamin $\mathrm{C}$ and $\mathrm{E}$, glutathione, carotenoids, and flavonoids [33, 77].

As mentioned earlier, RONS can be released by immune cells as a response to an inflammatory stimulus. Interestingly, during an inflammatory response phagocytic cells can 
directly produce RONS whereas in nonphagocytic cells their production is triggered by proinflammatory cytokines, such as IL-1 and IL-6 [22, 84]. In 1997, it was the first time reported that specific proinflammatory cytokines, IL1 , TNF- $\alpha$, and IFN- $\gamma$, generate ROS in nonphagocytic cells $[77,85]$. Later on, it was shown that IFN- $\gamma$, TNF- $\alpha$, and IL$1 \beta$ promote ROS through the induction of NOX1 in colon epithelium cells [78]. IFN- $\gamma$ also increases the expression level of the NOX2 isoform of NADPH oxidase in human macrophages and neutrophils as well as the expression of its DUOXA2-related enzyme in airway epithelial cells [78]. The anti-inflammatory cytokine TGF- $\beta$ induces NOX4 expression in many cell types, such as cardiac fibroblasts, smooth muscle cells, and hepatocytes. IL-4 and IL-13 antiinflammatory cytokines augment the expression level of DUOXA1 enzyme in airway epithelial cells [78, 86-89]. Recently, it was shown that the inflammatory mediator leukotriene $\mathrm{B}_{4}\left(\mathrm{LTB}_{4}\right)$ induces NOX1 in human mast cells [90]. Finally IL- 1, TNF- $\alpha$, and IFN- $\gamma$ proinflammatory cytokines stimulate the production of iNOS, which is inducibly expressed in macrophages, and thus contribute to the formation of nitric oxide as well as RNS [33, 91]. Overall, both pro- and anti-inflammatory cytokines have been shown to contribute to RNOS production through the induction of NADPH oxidase and iNOS activity. Interestingly, it has been shown that the proinflammatory cytokines seem to play a tumor promoting role while anti-inflammatory cytokines exert an antioncogenic function [22]. The latter leads to the suggestion of a potential link between inflammation, free radical-induced stress, and carcinogenesis.

\section{Free Radicals and Inflammatory-Induced Carcinogenesis}

Reactive Oxygen and Nitrogen Species (RONS) can be generated during inflammatory responses, and interestingly some inflammation-associated cancers are linked to oxidative and nitrosative stress. Examples include colorectal cancer provoked after active chronic colitis as well as lung, pancreatic, and esophageal cancers provoked after persistent inflammation of the bronchi, pancreas, and oesophagus respectively [33, 92-95]. In the previously mentioned cancer types either excessive free radical production or defective antioxidant mechanisms or both of these were observed.

Inflammation-mediated ROS production can trigger carcinogenesis either directly or indirectly [33]. Direct effects involve the formation of DNA cross-links, single- or doublestrand breaks leading to mutations in oncogenes and tumor suppressor genes and ultimately to genomic instability (Figure 1) [33, 77, 84, 96]. An example is the formation of an extremely reactive free radical species during inflammatory response, named peroxynitrite anion (ONOO-), produced by the reaction between the superoxide anion and nitric oxide, which can create DNA fragmentation [77]. Additionally, the hydroxyl radical is known to cause damage to the purine and pyrimidine bases as well as the deoxyribose backbone $[77,97]$. The most known DNA damage indicative of oxidative stress is the formation of 8-hydroxydeoxyguanosine
(8-OHdG) that is generated by the oxidative attack of $\mathrm{OH}^{\bullet}$ in the cell DNA [33]. Free radical production during inflammatory process can indirectly lead to carcinogenesis via ROS-mediated activation of signalling pathways (Figure 1) [33]. An important example is the involvement of oxidative stress in the activation of the transcription factor NF- $\kappa \mathrm{B}$ which in turn may display a protumorigenic effect, as mentioned earlier. Low to mild levels may lead to NF$\kappa \mathrm{B}$ expression, since $\mathrm{H}_{2} \mathrm{O}_{2}$ has been shown to degrade the $\mathrm{I} \kappa \mathrm{B} \alpha$ subunit, whereas high levels of oxidative stress in the cells may cause inhibition of NF- $\kappa \mathrm{B}$ expression $[33,98,99]$. Interestingly, growing evidence supports the fact that ROS act as second messengers in the NF- $\kappa \mathrm{B}$ activation through the proinflammatory cytokines TNF and IL-1 $[33,77]$. It is also worthwhile mentioning that iNOS can be induced by several stimuli, including cytokines as well as NF- $\kappa \mathrm{B}$ transcription factor $[22,100]$. Free radicals and cytokines can both either induce or become induced by NF- $\kappa \mathrm{B}$ and their generation by tumor cells in inflammation-induced cancers can actually create a positive feedback loop for their own production. The inflammatory microenvironment that develops around the tumors leads to additional production of cytokines and free radicals, which in turn favours the carcinogenesis process [22]. In addition, oxidative stress can cause MIN by reducing the enzymatic activity and expression of the DNA mismatch repair genes mutS homologs 2 and 6 [22,33]. Free radicals lead to gene silencing of the DNA mismatch repair gene $h M L H 1$ via hypermethylation induced by overexpression of DNA methyltransferases [22, 33].

Cancer development involves three stages, initiation, promotion, and progression, and oxidative stress is involved in all the previous. In the initiation stage, ROS promote DNA damage, such as 8 -OHdG formation, that may subsequently lead to gene mutations [33, 77]. During the promotion stage, low levels of oxidative stress can cause modifications in second messenger systems and promote cell division and proliferation $[33,77]$. Finally in the progression stage, ROS can create additional genetic alterations fuelling cancer cells with further evolutionary advantages [33, 77]. Overall, the action of RONS is dosedependent within a particular cell context often with tumor-promoting activity in low levels, whereas in high levels they may raise the antitumor barriers, namely, apoptosis and senescence [33].

\section{Future Perspectives}

Cytokines display pleiotropic actions ranging from tumorprotective to tumor-promoting activity in a spatial and temporal manner. The fact that certain cytokines display growth factor activity as well as the ability to produce RONS suggests that they may promote genomic instability in chronic inflammatory conditions. This is particularly significant taking into account the central role of cytokines as mediators of inflammation, a knowledge that can be exploited in future cancer therapeutic strategies. IL-2 and IL-15 are currently tested for their therapeutic potential in cancer [53]. It has been shown that IL-15 plays an important role in the antitumor efficacy of combination therapy with Imatinib 
Mesylate (IM), a tyrosine kinase inhibitor, and IL-2 in a mouse lung metastasis model, inducing a CCL2-dependent chemoattraction of IFN-producing killer dendritic cells (IKDCs) in the tumor microenvironment [101]. The latter finding has been exploited therapeutically by launching phase I clinical trial targeting IM-resistant gastrointestinal sarcomas and TRAIL-sensitive cancers. CCL2 serves as another paradigm of translation of molecular biology to clinical practice $[69,102]$. Although there are conflicting data regarding the role of CCL2 in carcinogenesis, it seems that it promotes prostate cancer development. Therefore, a neutralizing antibody against CCL2 is under clinical trials in prostate cancer. Conclusively, elucidation of the molecular mechanisms implicated in tumor-host interactions may provide new insight in understanding tumor development as well as provide additional future prospects for more effective and targeted cancer therapy and prevention.

\section{Acknowledgments}

The authors would like to thank Antonia Daleziou for her help and comments in preparing the paper. This work was supported by SARG-NKUA 70/3/8916 Grant.

\section{References}

[1] S. I. Grivennikov, F. R. Greten, and M. Karin, "Immunity, inflammation, and cancer," Cell, vol. 140, no. 6, pp. 883-899, 2010.

[2] P. Ehrilch, "Ueber den jetzigen stand der karzinomforschung," Nederlands Tijdschrift voor Geneeskunde, vol. 5, part 1, pp. 273-290, 1909.

[3] L. Thomas, "Discussion," in Cellular and Humoral Aspects of the Hypersensitive States, H. S. Lawrence, Ed., pp. 529-532, Hoeber-Harper, New York, NY, USA, 1959.

[4] F. M. Burnet, "The concept of immunological surveillance," Progress in Experimental Tumor Research, vol. 13, pp. 1-27, 1970.

[5] G. P. Dunn, L. J. Old, and R. D. Schreiber, "The three Es of cancer immunoediting," Annual Review of Immunology, vol. 22, pp. 329-360, 2004.

[6] D. Hanahan and R. A. Weinberg, "Hallmarks of cancer: the next generation," Cell, vol. 144, no. 5, pp. 646-674, 2011.

[7] B. F. Zamarron and W. Chen, "Dual roles of immune cells and their factors in cancer development and progression," International Journal of Biological Sciences, vol. 7, no. 5, pp. 651-658, 2011.

[8] J. Han and R. J. Ulevitch, "Limiting inflammatory responses during activation of innate immunity," Nature Immunology, vol. 6, no. 12, pp. 1198-1205, 2005.

[9] E. Shacter and S. A. Weitzman, "Chronic inflammation and cancer," Oncology, vol. 16, no. 2, pp. 217-230, 2002.

[10] W. W. Lin and M. Karin, "A cytokine-mediated link between innate immunity, inflammation, and cancer," Journal of Clinical Investigation, vol. 117, no. 5, pp. 1175-1183, 2007.

[11] S. Akira, S. Uematsu, and O. Takeuchi, "Pathogen recognition and innate immunity," Cell, vol. 124, no. 4, pp. 783-801, 2006.

[12] M. M. Markiewski and J. D. Lambris, "Is complement good or bad for cancer patients? A new perspective on an old dilemma," Trends in Immunology, vol. 30, no. 6, pp. 286-292, 2009.

[13] V. Bergonzini, C. Salata, A. Calistri, C. Parolin, and G. Palù, "View and review on viral oncology research," Infectious Agents and Cancer, vol. 5, no. 1, p. 11, 2010.

[14] H. Takahashi, H. Ogata, R. Nishigaki, D. H. Broide, and M. Karin, "Tobacco smoke promotes lung tumorigenesis by triggering IKK $\beta$ - and JNK1-dependent inflammation," Cancer Cell, vol. 17, no. 1, pp. 89-97, 2010.

[15] A. Mantovani, P. Allavena, A. Sica, and F. Balkwill, "Cancerrelated inflammation,” Nature, vol. 454, no. 7203, pp. 436444, 2008.

[16] C. Dostert, V. Pétrilli, R. Van Bruggen, C. Steele, B. T. Mossman, and J. Tschopp, "Innate immune activation through Nalp3 inflammasome sensing of asbestos and silica," Science, vol. 320, no. 5876, pp. 674-677, 2008.

[17] R. N. Apte and E. Voronov, "Is interleukin-1 a good or bad 'guy' in tumor immunobiology and immunotherapy?" Immunological Reviews, vol. 222, no. 1, pp. 222-241, 2008.

[18] J. Terzić, S. Grivennikov, E. Karin, and M. Karin, "Inflammation and colon cancer," Gastroenterology, vol. 138, no. 6, pp. 2101-e5, 2010.

[19] D. I. Gabrilovich and S. Nagaraj, "Myeloid-derived suppressor cells as regulators of the immune system," Nature Reviews Immunology, vol. 9, no. 3, pp. 162-174, 2009.

[20] S. K. Biswas and A. Mantovani, "Macrophage plasticity and interaction with lymphocyte subsets: cancer as a paradigm," Nature Immunology, vol. 11, no. 10, pp. 889-896, 2010.

[21] J. Condeelis and J. W. Pollard, "Macrophages: obligate partners for tumor cell migration, invasion, and metastasis," Cell, vol. 124, no. 2, pp. 263-266, 2006.

[22] A. J. Schetter, N. H. H. Heegaard, and C. C. Harris, "Inflammation and cancer: interweaving microRNA, free radical, cytokine and p53 pathways," Carcinogenesis, vol. 31, no. 1, Article ID bgp272, pp. 37-49, 2009.

[23] F. R. Balkwill, "The chemokine system and cancer," The Journal of Pathology, vol. 226, no. 2, pp. 148-157, 2012.

[24] J. B. Swann and M. J. Smyth, "Immune surveillance of tumors," Journal of Clinical Investigation, vol. 117, no. 5, pp. 1137-1146, 2007.

[25] H. Yu, D. Pardoll, and R. Jove, "STATs in cancer inflammation and immunity: a leading role for STAT3," Nature Reviews Cancer, vol. 9, no. 11, pp. 798-809, 2009.

[26] S. I. Grivennikov and M. Karin, "Dangerous liaisons: STAT3 and NF- $\kappa \mathrm{B}$ collaboration and crosstalk in cancer," Cytokine and Growth Factor Reviews, vol. 21, no. 1, pp. 11-19, 2010.

[27] C. Ferrone and G. Dranoff, "Dual roles for immunity in gastrointestinal cancers," Journal of Clinical Oncology, vol. 28, no. 26, pp. 4045-4051, 2010.

[28] M. Karin, "Nuclear factor $-\kappa \mathrm{B}$ in cancer development and progression," Nature, vol. 441, no. 7092, pp. 431-436, 2006.

[29] N. D. Perkins, "Integrating cell-signalling pathways with NF$\kappa \mathrm{B}$ and IKK function," Nature Reviews Molecular Cell Biology, vol. 8, no. 1, pp. 49-62, 2007.

[30] R. Zenz and E. F. Wagner, "Jun signalling in the epidermis: from developmental defects to psoriasis and skin tumors," International Journal of Biochemistry and Cell Biology, vol. 38, no. 7, pp. 1043-1049, 2006.

[31] Y. Carmi, E. Voronov, S. Dotan et al., "The role of macrophage-derived IL-1 in induction and maintenance of angiogenesis," Journal of Immunology, vol. 183, no. 7, pp. 47054714, 2009.

[32] M. Elkabets, V. S. G. Ribeiro, C. A. Dinarello et al., "IL$1 \beta$ regulates a novel myeloid-derived suppressor cell subset 
that impairs NK cell development and function," European Journal of Immunology, vol. 40, no. 12, pp. 3347-3357, 2010.

[33] S. Reuter, S. C. Gupta, M. M. Chaturvedi, and B. B. Aggarwal, "Oxidative stress, inflammation, and cancer: how are they linked?" Free Radical Biology and Medicine, vol. 49, no. 11, pp. 1603-1616, 2010.

[34] D. J. J. Waugh and C. Wilson, "The interleukin-8 pathway in cancer," Clinical Cancer Research, vol. 14, no. 21, pp. 67356741, 2008.

[35] H. Yang, M. Bocchetta, B. Kroczynska et al., "TNF- $\alpha$ inhibits asbestos-induced cytotoxicity via a NF- $\kappa \mathrm{B}$-dependent pathway, a possible mechanism for asbestos-induced oncogenesis," Proceedings of the National Academy of Sciences of the United States of America, vol. 103, no. 27, pp. 10397-10402, 2006.

[36] M. L. Cho, J. W. Kang, Y. M. Moon et al., "STAT3 and NF$\kappa \mathrm{B}$ signal pathway is required for IL-23-mediated IL-17 production in spontaneous arthritis animal model IL-1 receptor antagonist-deficient mice," Journal of Immunology, vol. 176, no. 9, pp. 5652-5661, 2006.

[37] J. S. Hao and B. E. Shan, "Immune enhancement and antitumour activity of IL-23," Cancer Immunology, Immunotherapy, vol. 55, no. 11, pp. 1426-1431, 2006.

[38] K. W. Moore, R. W. Malefyt, R. L. Coffman, and A. O'Garra, "Interleukin-10 and the interleukin-10 receptor," Annual Review of Immunology, vol. 19, pp. 683-765, 2001.

[39] S. Alas, C. Emmanouilides, and B. Bonavida, "Inhibition of interleukin 10 by Rituximab results in down-regulation of Bcl-2 and sensitization of B-cell non-Hodgkin's lymphoma to apoptosis," Clinical Cancer Research, vol. 7, no. 3, pp. 709$723,2001$.

[40] S. B. Jakowlew, "Transforming growth factor- $\beta$ in cancer and metastasis," Cancer and Metastasis Reviews, vol. 25, no. 3, pp. 435-457, 2006.

[41] F. Rodier, J. P. Coppé, C. K. Patil et al., "Persistent DNA damage signalling triggers senescence-associated inflammatory cytokine secretion," Nature Cell Biology, vol. 11, no. 8, pp. 973-979, 2009.

[42] G. P. Dimri, "What has senescence got to do with cancer?" Cancer Cell, vol. 7, no. 6, pp. 505-512, 2005.

[43] M. Fumagalli and F. d'Adda di Fagagna, "SASPense and DDRama in cancer and ageing," Nature Cell Biology, vol. 11, no. 8, pp. 921-923, 2009.

[44] V. G. Gorgoulis and T. D. Halazonetis, "Oncogene-induced senescence: the bright and dark side of the response," Current Opinion in Cell Biology, vol. 22, no. 6, pp. 816-827, 2010.

[45] J. C. Acosta and J. Gil, "A role for CXCR2 in senescence, but what about in cancer?" Cancer Research, vol. 69, no. 6, pp. 2167-2170, 2009.

[46] A. V. Orjalo, D. Bhaumik, B. K. Gengler, G. K. Scott, and J. Campisi, "Cell surface-bound IL- $1 \alpha$ is an upstream regulator of the senescence-associated IL-6/IL-8 cytokine network," Proceedings of the National Academy of Sciences of the United States of America, vol. 106, no. 40, pp. 17031-17036, 2009.

[47] S. Negrini, V. G. Gorgoulis, and T. D. Halazonetis, "Genomic instability an evolving hallmark of cancer," Nature Reviews Molecular Cell Biology, vol. 11, no. 3, pp. 220-228, 2010.

[48] V. G. Gorgoulis, L. V. F. Vassiliou, P. Karakaidos et al., "Activation of the DNA damage checkpoint and genomic instability in human precancerous lesions," Nature, vol. 434, no. 7035, pp. 907-913, 2005.

[49] T. D. Halazonetis, V. G. Gorgoulis, and J. Bartek, "An oncogene-induced DNA damage model for cancer development," Science, vol. 319, no. 5868, pp. 1352-1355, 2008.
[50] W. C. Burhans and M. Weinberger, "DNA replication stress, genome instability and aging," Nucleic Acids Research, vol. 35, no. 22, pp. 7545-7556, 2007.

[51] K. Aziz, S. Nowsheen, G. Pantelias, G. Iliakis, V. G. Gorgoulis, and A. G. Georgakilas, "Targeting DNA damage and repair: embracing the pharmacological era for successful cancer therapy," Pharmacology and Therapeutics, vol. 133, no. 3, pp. 334-350, 2012.

[52] J. Bartkova, Z. Horejsi, K. Koed et al., "DNA damage response as a candidate anti-cancer barrier in early human tumorigenesis," Nature, vol. 434, no. 7035, pp. 864-870, 2005.

[53] T. A. Waldmann, "The biology of interleukin-2 and interleukin-15: implications for cancer therapy and vaccine design," Nature Reviews Immunology, vol. 6, no. 8, pp. 595-601, 2006.

[54] M. Martinez-Moczygemba and D. P. Huston, "Biology of common $\beta$ receptor-signaling cytokines: IL-3, IL-5, and GMCSF," Journal of Allergy and Clinical Immunology, vol. 112, no. 4, pp. 653-666, 2003.

[55] T. Hosoyama, M. I. Aslam, J. Abraham et al., "IL-4R drives dedifferentiation, mitogenesis, and metastasis in rhabdomyosarcoma," Clinical Cancer Research, vol. 17, no. 9, pp. 2757-2766, 2011.

[56] N. Geijsen, L. Koenderman, and P. J. Coffer, "Specificity in cytokine signal transduction: lessons learned from the IL3/IL-5/GM-CSF receptor family," Cytokine and Growth Factor Reviews, vol. 12, no. 1, pp. 19-25, 2001.

[57] Y. Sawa, Y. Arima, H. Ogura et al., "Hepatic interleukin-7 expression regulates T cell responses," Immunity, vol. 30, no. 3, pp. 447-457, 2009.

[58] L. Knoops and J. C. Renauld, "IL-9 and its receptor: from signal transduction to tumorigenesis," Growth Factors, vol. 22, no. 4, pp. 207-215, 2004.

[59] T. Blankenstein, "The role of tumor stroma in the interaction between tumor and immune system," Current Opinion in Immunology, vol. 17, no. 2, pp. 180-186, 2005.

[60] P. C. Heinrich, I. Behrmann, S. Haan, H. M. Hermanns, G. Müller-Newen, and F. Schaper, "Principles of interleukin (IL)-6-type cytokine signalling and its regulation," Biochemical Journal, vol. 374, no. 1, pp. 1-20, 2003.

[61] W. T. Watford, B. D. Hissong, J. H. Bream, Y. Kanno, L. Muul, and J. J. O'Shea, "Signaling by IL-12 and IL-23 and the immunoregulatory roles of STAT4," Immunological Reviews, vol. 202, pp. 139-156, 2004.

[62] M. Wills-Karp, "Interleukin-13 in asthma pathogenesis," Immunological Reviews, vol. 202, pp. 175-190, 2004.

[63] S. Nogami, S. Satoh, M. Nakano et al., "Taxilin; a novel syntaxin-binding protein that is involved in $\mathrm{Ca}^{2+}$-dependent exocytosis in neuroendocrine cells," Genes to Cells, vol. 8, no. 1, pp. 17-28, 2003.

[64] W. Cruikshank and F. Little, "Interleukin-16: the ins and outs of regulating T-cell activation," Critical Reviews in Immunology, vol. 28, no. 6, pp. 467-483, 2008.

[65] M. Numasaki, M. Watanabe, T. Suzuki et al., "IL-17 enhances the net angiogenic activity and in vivo growth of human non-small cell lung cancer in SCID mice through promoting CXCR-2-dependent angiogenesis," Journal of Immunology, vol. 175, no. 9, pp. 6177-6189, 2005.

[66] F. Benchetrit, A. Ciree, V. Vives et al., "Interleukin-17 inhibits tumor cell growth by means of a T-cell-dependent mechanism," Blood, vol. 99, no. 6, pp. 2114-2121, 2002.

[67] S. Lebel-Binay, A. Berger, F. Zinzindohoué et al., "Interleukin-18: biological properties and clinical implications," European Cytokine Network, vol. 11, no. 1, pp. 15-25, 2000. 
[68] J. K. Kundu and Y. J. Surh, "Emerging avenues linking inflammation and cancer," Free Radical Biology \& Medicine, vol. 52, no. 9, pp. 2013-2037, 2012.

[69] J. Zhang, L. Patel, and K. J. Pienta, "Targeting chemokine (C$\mathrm{C}$ motif) Ligand $2\left(\mathrm{CCL}_{2}\right)$ as an example of translation of cancer molecular biology to the clinic," Progress in Molecular Biology and Translational Science C, vol. 95, pp. 31-53, 2010.

[70] B. Homey, A. Müller, and A. Zlotnik, "Chemokines: agents for the immunotherapy of cancer?" Nature Reviews Immunology, vol. 2, no. 3, pp. 175-184, 2002.

[71] A. P. Vicari, S. Ait-Yahia, K. Chemin, A. Mueller, A. Zlotnik, and C. Caux, "Antitumor effects of the mouse chemokine 6Ckine/SLC through angiostatic and immunological mechanisms," Journal of Immunology, vol. 165, no. 4, pp. 19922000, 2000.

[72] A. Müller, B. Homey, H. Soto et al., "Involvement of chemokine receptors in breast cancer metastasis," Nature, vol. 410, no. 6824 , pp. 50-56, 2001.

[73] N. Karin, "The multiple faces of CXCL12 (SDF-1 $\alpha$ ) in the regulation of immunity during health and disease," Journal of Leukocyte Biology, vol. 88, no. 3, pp. 463-473, 2010.

[74] D. Blanco, S. Vicent, M. F. Fragaz et al., "Molecular analysis of a multistep lung cancer model induced by chronic inflammation reveals epigenetic regulation of p16 and activation of the DNA damage response pathway," Neoplasia, vol. 9, no. 10, pp. 840-852, 2007.

[75] S. Cianfarani, B. Tedeschi, D. Germani et al., "In vitro effects of growth hormone $(\mathrm{GH})$ and insulin-like growth factor I and II (IGF-I and -II) on chromosome fragility and p53 protein expression in human lymphocytes," European Journal of Clinical Investigation, vol. 28, no. 1, pp. 41-47, 1998.

[76] V. J. Thannickal and B. L. Fanburg, "Reactive oxygen species in cell signaling," American Journal of Physiology-Lung Cellular and Molecular Physiology, vol. 279, no. 6, pp. L1005L1028, 2000.

[77] M. Valko, C. J. Rhodes, J. Moncol, M. Izakovic, and M. Mazur, "Free radicals, metals and antioxidants in oxidative stress-induced cancer," Chemico-Biological Interactions, vol. 160 , no. 1 , pp. 1-40, 2006.

[78] M. Katsuyama, "NOX/NADPH oxidase, the superoxidegenerating enzyme: its transcriptional regulation and physiological roles," Journal of Pharmacological Sciences, vol. 114, no. 2, pp. 134-146, 2010.

[79] P. Ghafourifar and E. Cadenas, "Mitochondrial nitric oxide synthase," Trends in Pharmacological Sciences, vol. 26, no. 4, pp. 190-195, 2005.

[80] A. Pautz, J. Art, S. Hahn, S. Nowag, C. Voss, and H. Kleinert, "Regulation of the expression of inducible nitric oxide synthase," Nitric Oxide, vol. 23, no. 2, pp. 75-93, 2010.

[81] C. J. Lowenstein and E. Padalko, "iNOS (NOS2) at a glance," Journal of Cell Science, vol. 117, no. 14, pp. 2865-2867, 2004.

[82] G. Poli, G. Leonarduzzi, F. Biasi, and E. Chiarpotto, "Oxidative stress and cell signalling," Current Medicinal Chemistry, vol. 11, no. 9, pp. 1163-1182, 2004.

[83] M. Liontos, I. S. Pateras, K. Evangelou, and V. G. Gorgoulis, "The tumor suppressor gene ARF as a sensor of oxidative stress," Current Molecular Medicine. In press.

[84] S. P. Hussain, L. J. Hofseth, and C. C. Harris, "Radical causes of cancer," Nature Reviews Cancer, vol. 3, no. 4, pp. 276-285, 2003.

[85] I. L. C. Chapple, "Reactive oxygen species and antioxidants in inflammatory diseases," Journal of Clinical Periodontology, vol. 24, no. 5, pp. 287-296, 1997.
[86] A. Sturrock, B. Cahill, K. Norman et al., "Transforming growth factor- $\beta 1$ induces Nox4 NAD $(\mathrm{P}) \mathrm{H}$ oxidase and reactive oxygen species-dependent proliferation in human pulmonary artery smooth muscle cells," American Journal of Physiology-Lung Cellular and Molecular Physiology, vol. 290, no. 4, pp. L661-L673, 2006.

[87] A. Sturrock, T. P. Huecksteadt, K. Norman et al., "Nox4 mediates TGF- $\beta 1$-induced retinoblastoma protein phosphorylation, proliferation, and hypertrophy in human airway smooth muscle cells," American Journal of Physiology-Lung Cellular and Molecular Physiology, vol. 292, no. 6, pp. L1543L1555, 2007.

[88] I. Cucoranu, R. Clempus, A. Dikalova et al., "NAD(P)H oxidase 4 mediates transforming growth factor- $\beta 1$-induced differentiation of cardiac fibroblasts into myofibroblasts," Circulation Research, vol. 97, no. 9, pp. 900-907, 2005.

[89] I. Carmona-Cuenca, C. Roncero, P. Sancho et al., "Upregulation of the NADPH oxidase NOX4 by TGF-beta in hepatocytes is required for its pro-apoptotic activity," Journal of Hepatology, vol. 49, no. 6, pp. 965-976, 2008.

[90] G. Y. Kim, J. W. Lee, H. C. Ryu, J. D. Wei, C. M. Seong, and J. H. Kim, "Proinflammatory cytokine IL- $1 \beta$ stimulates IL-8 synthesis in mast cells via a leukotriene B4 receptor 2-linked pathway, contributing to angiogenesis," Journal of Immunology, vol. 184, no. 7, pp. 3946-3954, 2010.

[91] M. Valko, D. Leibfritz, J. Moncol, M. T. D. Cronin, M. Mazur, and J. Telser, "Free radicals and antioxidants in normal physiological functions and human disease," International Journal of Biochemistry and Cell Biology, vol. 39, no. 1, pp. 44-84, 2007.

[92] A. Roessner, D. Kuester, P. Malfertheiner, and R. SchneiderStock, "Oxidative stress in ulcerative colitis-associated carcinogenesis," Pathology Research and Practice, vol. 204, no. 7, pp. 511-524, 2008.

[93] C. A. Martey, S. J. Pollock, C. K. Turner et al., "Cigarette smoke induces cyclooxygenase- 2 and microsomal prostaglandin E2 synthase in human lung fibroblasts: implications for lung inflammation and cancer," American Journal of Physiology, vol. 287, no. 5, pp. L981-L991, 2004.

[94] G. Garcea, A. R. Dennison, W. P. Steward, and D. P. Berry, "Role of inflammation in pancreatic carcinogenesis and the implications for future therapy," Pancreatology, vol. 5, no. 6, pp. 514-529, 2005.

[95] S. J. Murphy, L. A. Anderson, B. T. Johnston et al., "Have patients with esophagitis got an increased risk of adenocarcinoma? Results from a population-based study," World Journal of Gastroenterology, vol. 11, no. 46, pp. 7290-7295, 2005.

[96] R. Visconti and D. Grieco, "New insights on oxidative stress in cancer," Current Opinion in Drug Discovery and Development, vol. 12, no. 2, pp. 240-245, 2009.

[97] M. Dizdaroglu, P. Jaruga, M. Birincioglu, and H. Rodriguez, "Free radical-induced damage to DNA: mechanisms and measurement," Free Radical Biology and Medicine, vol. 32, no. 11, pp. 1102-1115, 2002.

[98] G. Gloire, S. Legrand-Poels, and J. Piette, "NF- $\kappa$ B activation by reactive oxygen species:fifteen years later," Biochemical Pharmacology, vol. 72, no. 11, pp. 1493-1505, 2006.

[99] W. Dröge, "Free radicals in the physiological control of cell function," Physiological Reviews, vol. 82, no. 1, pp. 47-95, 2002.

[100] S. P. Hussain and C. C. Harris, "Inflammation and cancer: an ancient link with novel potentials," International Journal of Cancer, vol. 121, no. 11, pp. 2373-2380, 2007. 
[101] G. Mignot, E. Ullrich, M. Bonmort et al., "The critical role of IL-15 in the antitumor effects mediated by the combination therapy imatinib and IL-2," Journal of Immunology, vol. 180, no. 10, pp. 6477-6483, 2008.

[102] M. G. Lechner, S. M. Russell, R. S. Bass, and A. L. Epstein, "Chemokines, costimulatory molecules and fusion proteins for the immunotherapy of solid tumors," Immunotherapy, vol. 3, no. 11, pp. 1317-1340, 2011. 

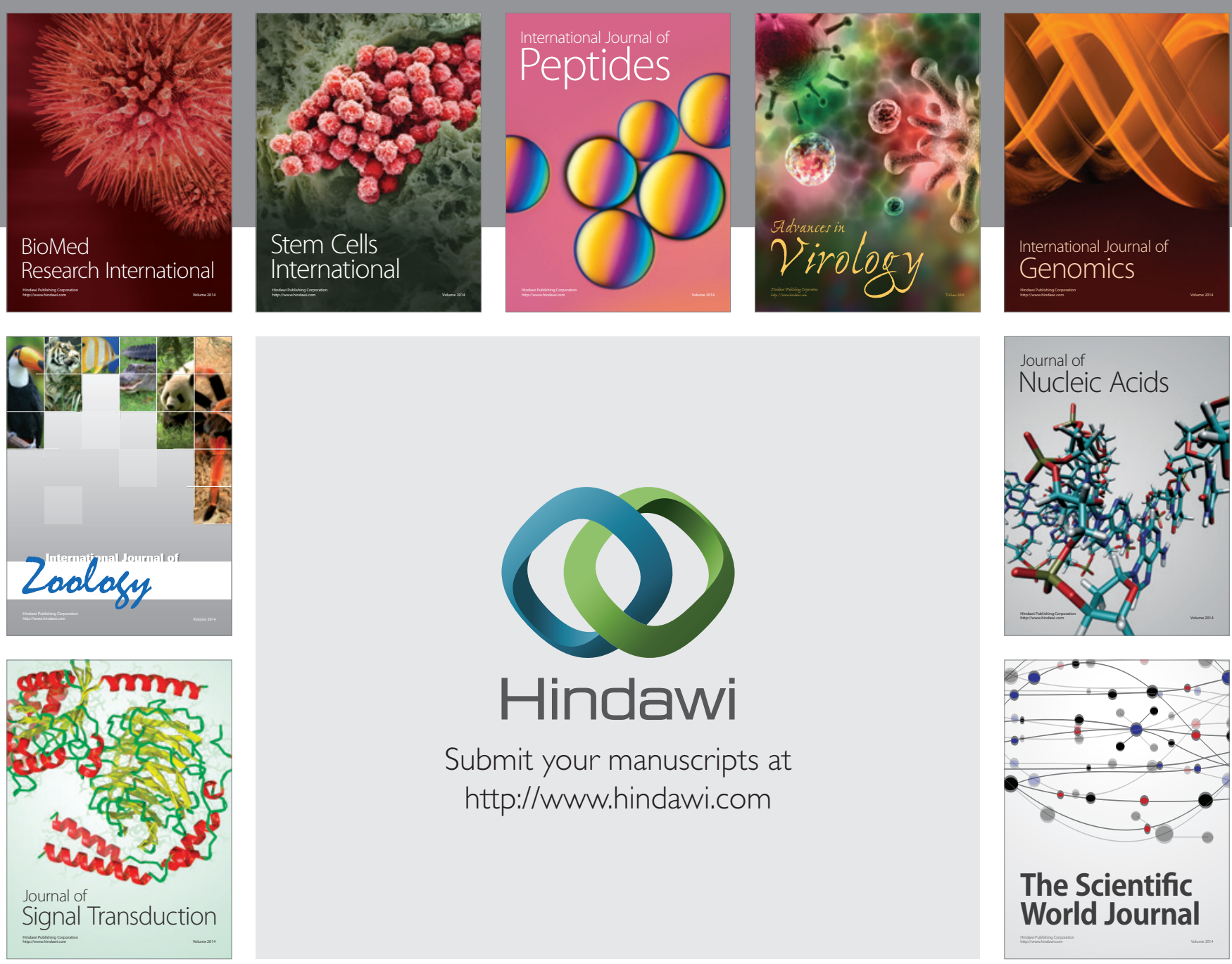

Submit your manuscripts at

http://www.hindawi.com
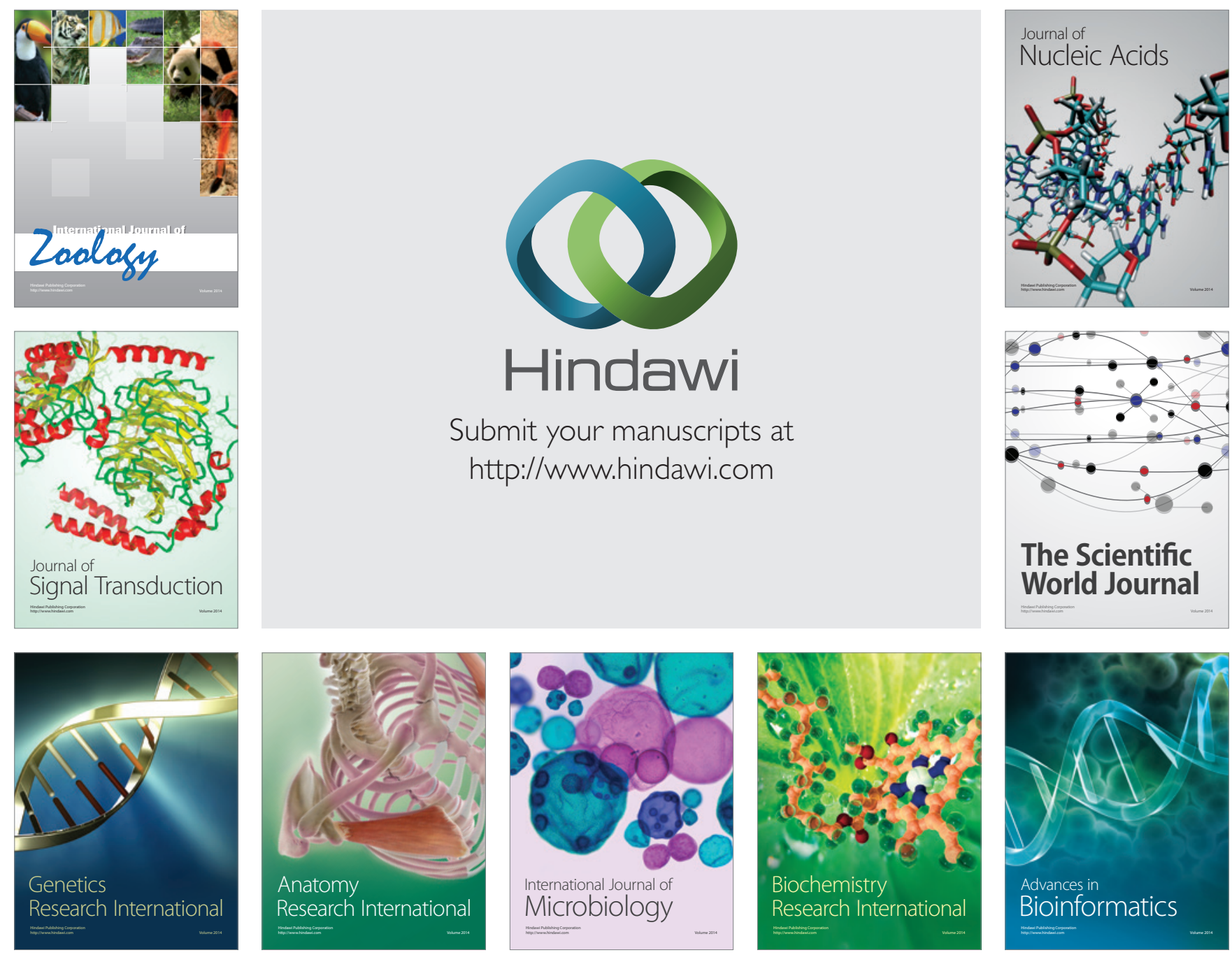

The Scientific World Journal
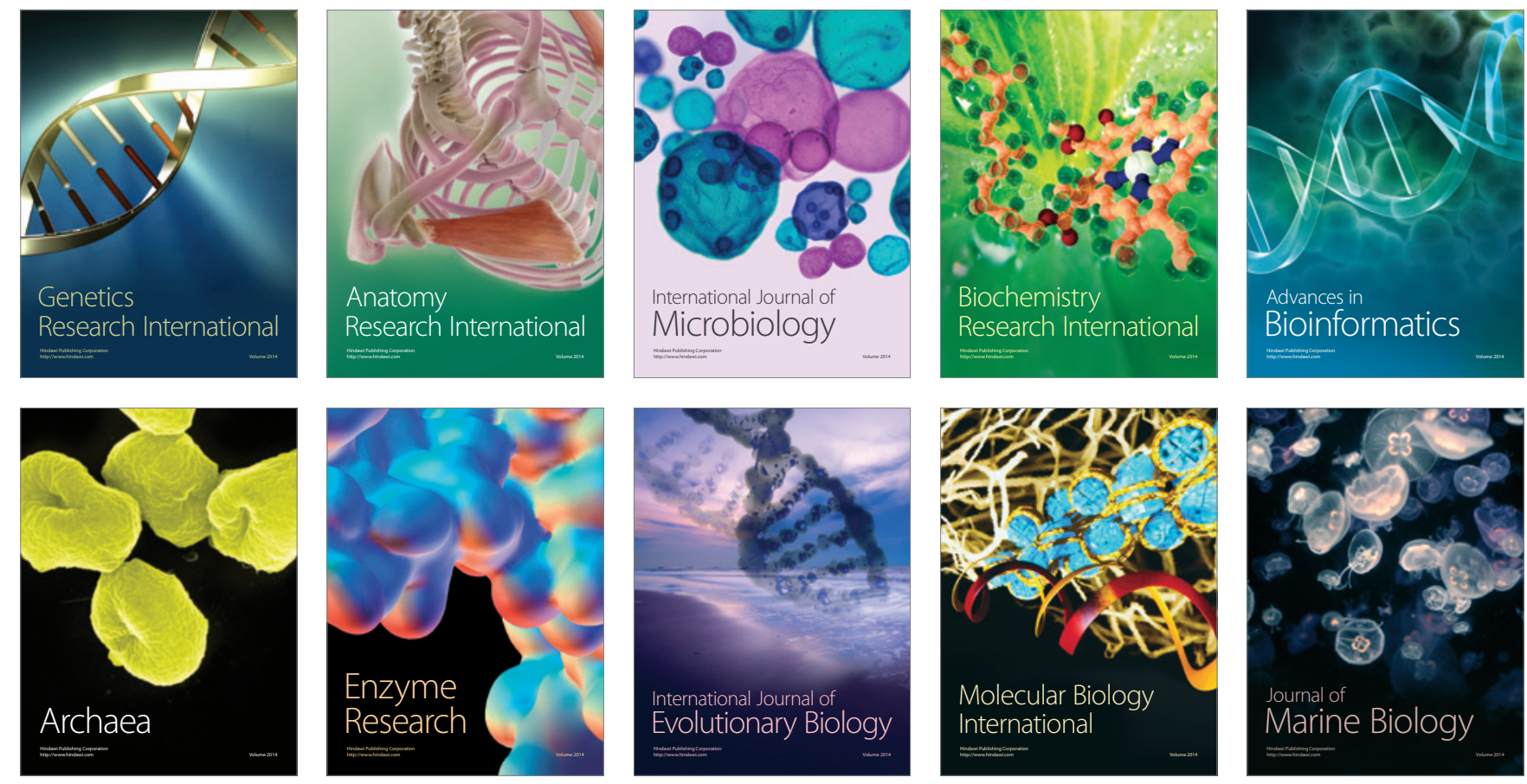